\title{
Doğum Sonu Dönemde Evde Bakım ve Perinatoloji Hemşiresinin Gelişen Rolleri
}

\author{
Postpartum Home Care and Developing Roles of Perinatology Nurses
}

\author{
Özen İNAM ${ }^{1}$ (D), Ümran YEŞiLTEPE OSKAY² (iD
}

ÖZ

Perinatoloji hemşireliği ile kadın sağlığını gebelik sürerken, doğum esnasında ve doğum sonu dönemde korumak ve geliştirmek hedeflenmektedir. $\mathrm{Bu}$ hedef doğrultusunda perinatoloji hemşiresi gebeyi ve lohusayı evde takip edip, evde bakımını gerçekleştirebilmektedir. Perinatolojide evde bakım uygulamaları; hastane yatışlarının kısalması ve evde bakımın kadının konforu ile bağımsızlığını artırması gibi pek çok olumlu nedenlerle daha fazla önem kazanmaya başlamıştır. Özellikle doğum sonrası, hastaneden taburcu olduktan sonra lohusa ve bebeğinin sağlığının korunması açısından evde takibinin yapılması için ev ziyaretlerinin planlanması önemlidir. Bunların yanı sıra ailenin ebeveynliğe hazırlığı, bebek bakımı gibi konularda eğitim ve desteğe ihtiyacı olmaktadır. Ev ziyaretleri ve evde bakım özellikle Avrupa ülkelerinde; hemşirelerin perinatoloji alanında profesyonelleşmesi, kanıta dayalı uygulamaları benimsemesi, modeller geliştirmesi ve teknolojiden yararlanması ile optimal düzeye ulaşmaktadır. Bu makale ile perinatoloji alanında doğum sonu evde bakımın önemi ve perinatoloji hemşiresinin gelişen rollerini tartışmak amaçlanmıştır. $\mathrm{Bu}$ amaç doğrultusunda perinatolojide evde bakımda yapılması gerekenler ile perinatoloji hemşiresinin görevleri ve değişen teknoloji ile gelişen rolleri vurgulanmıştır. Sonuç olarak; ülkemizde perinatoloji alanında özellikle doğum sonu dönemde ev ziyaretlerine daha fazla önem verilmesi ve bu konuda dünyadaki yenilikler örnek alınarak çeşitli programlar oluşturulması ve teknolojiden daha fazla yararlanılması önerilebilir.

Anahtar Kelimeler: Doğum sonrası bakım, Evde bakım, Perinatoloji.

\begin{abstract}
Perinatology nursing aims to protect and improve women's health during pregnancy, delivery and postpartum period. In line with this goal, perinatology nurse can follow the pregnant and puerperant at home and perform home care. Home care practices in perinatology started to gain more importance due to many positive reasons such as shortening of hospital stays and home care, increasing the comfort and independence of women. The planning of home visits is important for the follow-up at home in order to protect the health of the woman and her baby after her discharge from the hospital. In addition to these, the family needs training and support on issues such as parenting preparation, baby care. Home visits and home care in European countries have evolved through the professionalization of nurses in perinatology, adopting evidence-based practices, developing models and benefiting from technology. The aim of this article is to discuss the importance of postnatal home care in the field of perinatology and the evolving roles of the perinatology nurse. For this purpose, the things to be done in home care in perinatology, the duties of the perinatology nurse and their developing roles with changing technology were emphasized. As a result; it is recommended to give more importance to home visits in the field of perinatology in our country especially during postpartum period and to create various programs by taking the innovations in the world as an example with the utilization of more technology.
\end{abstract}

Keywords: Postnatal care, Home care, Perinatology.

\section{GÍRİŞ}

Son yıllarda özellikle yaşlı nüfusun artışı, hastanelerin doluluk oranlarının artması ve uzun süre bakım gerektiren sağlık sorunları, sağlık hizmeti sunumuna olan gereksinimi arttırmaktadır. Bunun yanı sıra hastanelerde uzun yatış gerektiren kronik hastalıkların artışı veya rehabilitasyon gerektiren durumlara çözüm olarak evde bakım ve ziyaretler ön plana çıkmaktadır. Kronik hastalıklar ile rehabilitasyonu uzun süren durumlarda uzun hastane yatışları yerine evde bakım ve ziyaretler ile
Özen İNAM (西)

Maltepe Üniversitesi, Tıbbi Hizmetler ve Teknikler Bölümü, İlk ve Acil Yardım Programı, İstanbul

e-mail:ozeninam@maltepe.edu.tr

Ümran YEŞILLTEPE OSKAY

İstanbul Üniversitesi-Cerrahpaşa, Florence Nightingale Hemşirelik Fakültesi Kadın Sağlığı ve Hastalıkları Hemşireliği Anabilim Dalı, İstanbul 
hastaların izlenmesi sayesinde hastaların daha kısa sürede sosyal yaşamlarına geri dönebilmeleri de sağlanmaktadır (1).

Gebelerde ve lohusalarda da aynı şekilde evde ziyaretlerinin yapılması tüm dünyada olduğu gibi ülkemizde de önerilmektedir. Özellikle fetüsün veya annenin sağlığını tehdit edebilecek yüksek riskli gebeliklerin takibi açısından, evde bakım hizmetleri önem arz ederken, postpartum dönemde gerek annenin gerekse bebeğin ilk günlerdeki izlemi anne-bebek sağlığının korunması açısından çok önemlidir (2). Postpartum dönemde lohusa hem kendisinin hem de yenidoğan sağlık bakımıyla ilgili ihtiyaçlarını karşılamak zorunda kalmaktadır. Evde geçirdiği bu riskli dönemde çoğunlukla bir sağlık sorunu olmadığı sürece hastaneye başvurmamakta, doktor kontrol randevusu gelene kadar herhangi bir sağlık hizmeti almamaktadır. Oysa postpartum dönemde kadınlarda kanama, enfeksiyon, depresyon gibi sağlık sorunları, yenidoğanlarda ise emme problemleri, yenidoğan sarıllı̆̆ gibi sorunlar yaşanabilmektedir. Tüm bu süreçte anne-bebek sağlığını koruyup geliştirmede evde bakım hemşireleri önemli roller üstlenmektedir (3).

Avrupa'da 1900'lü yıllarda perinatolojide evde bakım ile ilgili yapılmış pek çok çalışmaya rastlanmakta, günümüzde ise modeller ile desteklenerek optimal seviyelere ulaştığ 1 söylenebilir. Ülkemizde ise perinatolojide evde bakım ile ilgili yapılan akademik çalışmaların azlı̆̆ı, perinatolojide ve doğum sonu dönemde evde bakım ziyaretlerinin anne ve bebek sağlığı açısında yararlarını değerlendirmek açısından yeterli değildir $(1,3)$. Temel Sağlık Hizmetleri Genel Müdürlügü istatistiklerine bakıldığında 2010 yılında lohusa başına yapılan ortalama izlem sayısının 1,5; 2016 y1lı verilerinde 3,1 olduğu görülmektedir. Yine de bu sayılar Dünya Sağlık Örgütü’nün önerisinin altındadır (1). $\mathrm{Bu}$ nedenle bu çalışma; doğum sonu dönemde evde bakım ve ev ziyaretlerini önemine dikkat çekmek amacıyla ilgili literatürün gözden geçirilmesi amacıyla yapılmıştır.

\section{Doğum Sonu Dönemde Evde Bakımın Önemi}

Perinatal evde bakım planlamasi; antenatal dönem, postpartum dönem ve yine doğum sonu dönemde yüksek riskli yenidoğanların bakımını içerir (4). Doğum sonu dönem ise gerek anne sağlığ1 gerekse yenidoğan sağlığ 1 açısından riskli bir dönem olup, lohusanın ve bebeğin izlemini gerektirmektedir. Doğum sonrası dönem lohusa için; kanama, enfeksiyon (idrar yolu, epizyo bölgesi, sezeryan insizyonu vb.), mastit, postpartum depresyon gibi önemli sağlık riskleri taşımaktadır. Yapılan bir çalışmada ev ziyareti yapılan deney gurubunda ilk altı hafta bahsedilen sağlık sorunlarını yaşama durumunun kontrol grubuna göre $\% 15$ az olduğu bulunmuştur (3). Ayrıca yenidoğan da; sarılık, pişik, pamukçuk, göbek kordonunda enfeksiyon gibi sağlık sorunları açısından risklidir (1, 3). Yapılan çalışmada ev ziyareti yapılan grupta yenidoğanda ilk altı haftada sorun yaşama durumu kontrol grubuna göre $\% 28$ daha az görülmüştür (3). Tüm bunların yanı sıra postpartum dönem annenin ebeveynlik rolüne alışma sürecini de kapsar. Anne, bebek bakımı ve ihtiyaçlarını öğrenme, bebeğin ihtiyaçlarını karşılamadaki yeterliliği gibi konularda eğitim ve desteğe ihtiyaç duyar. Bebeği emzirme, emzirme sorunlarıyla baş etme, bebeğin banyosu, alt değişimi, göbek bakımı gibi temel bakım ihtiyaçlarını yerine getirme ve bunları yaparken karşılaştı̆̆ı güçlükler ile baş etmede profesyonel birinden destek almak kadının stresini de azaltmaktadır (5). Tüm bu sağlık sorunlarının erken tespiti açısından ve lohusa ile ailenin eğitimi gibi konularda evde ziyaretinin yapılması şüphesiz tüm dünyada önemi vurgulanan ve önerilen bir sağlık hizmetidir. Literatürde doğum sonrası dönem evde bakım ve faydaları üzerine yapılmış pek çok çalışmada, evde bakım programları ile yukarda sayılan sorunların büyük oranda azaltılabildiği gösterilmiştir $(1,3,6-8)$.

Son dönemde pek çok Avrupa ülkesinde ve Türkiye'de pospartum erken taburculuk çeşitli nedenler ile bir sağllk politikası olarak uygulanmaktadır. Ülkemizde anne ya da bebeği açısından bir sağlık sorunu bulunmadığı sürece hastanede yatış süresi vajinal/normal doğum sonrası ortalama 12-24 saat, sezaryen ile doğum sonrası ise 2-5 gün olarak uygulanmaktadır (9). Kısalan hastane yatış süreleri beraberinde doğum sonu bakımın devamlılığının ev ziyaretleri ve evde bakım şeklinde yapılması ihtiyacını gündeme getirmektedir. Genel olarak postpartum ev ziyaretlerinin ilk 24-48 saat içinde yapılması daha sonraki ziyaretlerin ise 2-6 hafta sonrasina planlanması da önerilmektedir. Günümüzde Avusturalya, Hollanda, Norveç gibi ülkelerde gebelikten, lohusalık ve erken çocukluk dönemine kadar yoğun ev ziyaretlerinin uygulandığı gebelikten bebeğin iki yaşına gelinceye kadar takip edildiği, "right@home”, "Family Nurse Partnership (FNP)" gibi özel modellerin kullanıldığı ve optimum fayda sağladığ 1 belirtilmiştir (10). Bu nedenle dünyanın pek çok gelişmiş ülkesinde perinatal ev ziyaretlerinin devlet veya özel fonlarla destekli gelişmiş programlar ile yürütüldüğü görülmektedir (11). Türkiye'de Sağlik Hizmetlerinin 
Yürütülmesi Hakkındaki Yönerge’ye göre sağlık evlerinde çalışan personelin görevleri arasında ev ziyaretleri yaparak gebeleri tespit etmek, düzenli aralıklarla ziyaret etmek ve izlemek, riskli gebelikleri erken dönemde tespit ederek gerekli birimlere sevk etmek şeklinde yer almaktadır (12). Aile Hekimliği Uygulama Yönetmeliği (Revizyon: 2016) kapsamında ise Aile Hekimliği'nin, “gebe ve lohusa izlemi, bebek ve çocuk izlemi, üreme sağlığı ve bulaşıcı hastalıklar ile ilgili veriler ve Kurum tarafından belirlenen benzeri veriler evrak kayıt kriterlerine göre belirli aralıklarla düzenli olarak basılı veya elektronik ortamda Kuruma bildirme" görevleri mevcuttur (13). Görülmektedir ki ülkemizde yasalarla düzenlenmiş, net şekilde belirlenmiş perinatal ev ziyaret programları ve özel modeller bulunmamaktadır. Bu nedenle ev ziyaretleri yasalar ile desteklenerek Avrupa'daki modeller örnek alınarak daha etkin hale getirilebilir.

\section{Perinatolojide Evde Bakım Sirasında Tanılama Rehberi ve Uygulamalar}

Anneye, yenidoğana ve aileye gereksinimlerine yönelik bireysel evde bakım verilmeden önce, detaylı tanılama ve sorunları saptama ev ziyaretlerinin ilk basamağıdır. $\mathrm{Bu}$ sayede etkili ve bireysel bir evde bakım planı yapılabilir. Bu nedenle Amerika Birleşik Devletleri (ABD) Kadın Sağlığı Obstetrik ve Yenidoğan Hemşireleri Derneği (AWHONN), Amerikan Hemşireler Birliği (ANA), Amerikan Pediatri Akademisi (AAP) ve Amerikan Obstetri ve Jinekoloji Koleji (ACOG) anne ve yenidoğanın tanılanmasında rehber geliştirmiştir. Anne ve yenidoğan tanılaması "fiziksel tanılama, psikolojik tanılama, çevrenin tanılanması ve eğitim gereksinimi tanılaması" olmak üzere dört başlıkta toplanmıştır (14).

\section{Psikolojik Tanılama:}

Evde bakım sırasında "Psikolojik Tanılama" için değerlendirilmesi önerilen kriterler şöyledir; "anneyenidoğan etkileşim süreci, ebeveynliğe yönelik emosyonel yanıt, çocuk sahibi olmaya yönelik bakış açısı, aile içi iletişim, başa çıkma ve uyum becerileri, annelik rolüne uyum, beden imajı algısı, destek kişilerin belirlenmesi, sosyal, ekonomik ve kültürel faktörler, toplumdaki kaynaklarla ilgili bilgi durumu" olarak sıralanmaktadır.

\section{Çevre Tanılaması:}

"Çevre Tanılaması" için; "güvenlik konularının gözlenmesi, uygun 1s1 ve sıcaklığın kontrolü, telefon bulunması, yenidoğan karyolası, oyuncakları, ev hayvanları, ekipmanların (termometre, sekresyon aspiratörü, tırnak makası vb.)" değerlendirilmesi önerilmektedir (14).

\section{Fizyolojik Tanılama:}

"Fizyolojik Tanılama Kriterleri" iki alt kategoride değerlendirilmektedir;

I. Anneve yönelik tanulama kriterleri: "Vital bulgular (ateş, nabız, solunum, kan basınc1), meme ve meme uçlarının durumu, fundus yüksekliği; kıvamı ve pozisyonu, loşia; renk, içerik ve miktar, perine, epizyotomi, ödem, ağrı, eliminasyon durumu, idrar ve gaita yapma ile ilgili özellikler, beslenme durumu, uyku alışkanlıkları, emosyonel tanılama, postpartum annelik hüznü ya da depresyon, cinsel konular, kendine bakım yeteneği, aktivite düzeyi, ulaşllabilecek sosyal destek sistemleri, doğum sonu döneme yönelik kültürel ve dini normlar ve uygulamaların" sorgulanması ve değerlendirilmesi önerilmektedir (14).

\section{Yenidoğana vönelik fiziksel tanılama kriterleri:} "Vital bulgular (ateş, nabız, solunum), fontaneller, fizyolojik sarılık belirtileri, cildin durumu, renk, umblikal kord, sünnet insizyonu, refleksler, beslenme durumu, aldığı besinler, eliminasyon durumu, idrar ve gaita yapma sıklığı, uyku düzeni” değerlendirilmesi gereken alanlardır.

Ayrıca ev ziyaretleri sırasında aile eğitimi de büyük önem taşımakta olup; eğitim gereksinimleri aşağıdaki Tablo 1'de belirtilmişsir. 
Tablo 1. Eğitim gereksinimi tanılamas1

\begin{tabular}{|c|c|}
\hline Anneye y & Yenidoğana yönelik eğitim konuları \\
\hline - $\quad$ Perine bakımı & - $\quad$ Cilt bakımı ve banyo \\
\hline - $\quad$ Epizyo ve insizyon bakımı & - Umblikal kord bakımı \\
\hline - $\quad$ Beden imajı değişiklikleri & Sünnet bakımı \\
\hline Diyet ve sivı alımı & $\begin{array}{l}\text { - Normal hormonal etkiler, vajinal } \\
\text { akıntı ve meme dolgunluğu }\end{array}$ \\
\hline Cinsellik, Aile planlaması & Pişik bakımı \\
\hline Potansiyel kom & $\begin{array}{l}\text { - Yenidoğanın yatma ve tutma } \\
\text { pozisyonları }\end{array}$ \\
\hline - Hemşire, ebe ya da hekimin & • V Vücut 1SIS1 ölçümü \\
\hline nlar, doğum sonu & \\
\hline trolü ve emzirme & Normal büyüme ve gelişme \\
\hline de kullanılabilecek ağrı & \\
\hline $\begin{array}{l}\text { - Annelik hüznünün depresyon ve } \\
\text { psikozdan farkları }\end{array}$ & - $\quad$ Anne bebek etkileşimi \\
\hline - $\quad$ Aile içi şiddet & - Uyku-uyanıklık döngüsü \\
\hline Aktivite düzeyi ve normal & - Güvenlik konuları, araba \\
\hline günlük aktivite düzenine dönme & koltukları, hayvanlar, ilaçlar, \\
\hline zamanı, dinlenme gereksinimi & oyuncaklar \\
\hline Emzirme sıklığı, pozisyonu & Ağlama ve rahatlatma teknikleri \\
\hline Meme ve meme ucu bakımı & Hemşire, ebe ya da pediatristin \\
\hline & aranacağı durumlar, kontrol \\
\hline Emzirmenin yeterli olduğunu & $\begin{array}{ll} & \text { Sikilgi } \\
\text { • } & \text { Yeterli süt desteği ve dolgunluk }\end{array}$ \\
\hline & $\begin{array}{l}\text { - } \quad \text { Mama ile be } \\
\text { miktarı, s1kl }\end{array}$ \\
\hline
\end{tabular}

\section{Doğum Sonu Dönemde Teknoloji Kullanımı}

Teknolojinin gelişmesi ile sağlık kurumları ve sağlık hizmet sunumuna entegre edilmesi günümüzde giderek yaygınlaşmaktadır. Artan nüfus, personel yetersizliği, ulaşım imkanlarının güç olduğu koşullar gibi nedenlerle eve gitmenin zor olduğu durumlarda ya da ev ziyaretlerinin planlanmadığı günlerde lohusaların ve yeni doğanların takibini kolaylaştıran çeşitli teknolojik yöntemler geliştirildiği görülmektedir.

$\mathrm{Bu}$ yöntemlere örnek olarak Japonya'da doğum öncesi ve doğum sonrası sağlık hizmetleri için yeni bir telefon danışma servisi geliştirilmiştir ve ücretsiz bir cep telefonu numarası verilmiş ve bu numaradan anne ve yeni doğan bakımı uygulamalarında danışmanlık almak üzere eğitimli bir hemşireye ulaşmaları sağlanmıştır (15). Proje ayrıca çocuk yetiştirmeyi desteklemek için bilgi de sağlamıştır. Bu çalışma, Japonya'daki uzman hemşirelerin ve hizmet alanların telefon ya da sosyal ağ danışma hizmetinden duyduğu memnuniyetin yüksek olduğunu göstermiştir.
Başka bir çalışma örneği de ülkemizde yapılmış olup (16), prematüre yenidoğanların ebeveynlerine yönelik verilecek olan eğitimde internet alternatif bir yöntem olarak kullanılmış ve bir web tabanlı eğitimin bakıma yönelik özgüven ve kaygı düzeylerine etkisi değerlendirilmiştir. "http://kuvozdehayatvar.com" isimli web sitesi kullanılarak, çalışma grubundaki ebeveynlere üç haftalık planlı eğitim ve danışmanlık programı verilmiştir. Araştırma sonucunda uygulanan web tabanlı eğitimin prematüre yenidoğanların ailesinin/ebeveynlerin bebek bakımına yönelik özgüvenini artırma ve kaygı düzeylerini azaltmada etkili olduğu sonucuna ulaşılmıştır. Bu ve benzeri çalışmalar gösteriyor ki bazen iyi geliştirilmiş bir teknoloji kanalı ile ulaşılan sağlık hizmeti de birebir görüşme gibi etkili olabilmektedir.

\section{Perinatoloji Hemşiresinin Gelişen Rolleri}

“ABD'de Kadın Sağlığı, Obstetrik ve Yenidoğan Hemşireleri Derneği (AWHONN)" ve "Ulusal Kadın Sağlığı Hemşireliği Derneği (NPWH)", kadın sağllğ̣ hemşireliği uygulamalarını; birey, aile ile toplumun mevcut ve olası sağlık sorunlarının değerlendirilmesi, tanı ve tedavisinin sağlanması adına uzmanlık bilgisi gerektiren, dinamik ve özerk rolleri olan özel bir uygulama alanı olarak tanımlamaktadır (17). Dünyada son yıllarda yaşanan siyasi, makroekonomik, sosyal hayattaki değişim ve gelişmeler ile teknoloji ve bilimdeki hızlı keşifler; sağlı politikalarını da etkilemiş, bununla beraber sağlık profesyonellerinin rol ve sorumluluklarında da değişimlerin yaşanmasına sebep olmuştur. $\mathrm{Bu}$ gelişmelerin etkisinde perinatoloji alanında görev alan hemşirelerin de rol ve sorumluluklarında değişimler meydana gelmiştir. Gelişmiş ülkelerde perinatoloji hemşireliği genel sağlık hizmeti uygulamalarında gebe ve lohusa merkezli bütüncül bir yaklaşım sağlayan ileri hemşirelik uygulamalarının özel bir alanı olarak kabul edilmektedir. Perinatal hemşirelik uygulamaları "gebe ya da lohusa ile ailesinin değişen duruma fizyolojik, psikolojik ve sosyal açılardan uyum sağlayabilmesi adına bakım ve eğitim gereksinimlerinin karşılanması ve aileye rehber olmayı kapsamaktadır" (18) şeklinde tanımlanmaktadır. Perinatoloji hemşirelerinin uygulamada hastanedeki uygulamaların dışında, kadın sağlığının geliştirilmesi ve korunması adına eğitim verme, araştırma ve danışmanlık yapma ayrıca kadın haklarının savunuculuğu gibi pek çok rolü bulunmaktadır (19). Dünden bugüne perinatoloji hemşiresinin postpartum dönemdeki genel rolleri ise; 
- Sağlıklı yenidoğan bakımı

- Yenidoğana ilişkin sağlık sorunlarının tespit ve değerlendirilmesi

- Lohusa bakımı ile lohusanın sağlık sorunlarının tespit ve değerlendirilmesi

- Aile üyelerinin gebelik, doğum ve yenidoğana olumlu adaptasyonu olarak sayılabilir.

Hemşireler tarafindan verilen perinatal evde bakımın etkinliği eskiden beri yapılan çalışmalar ile desteklenmektedir (1, 6, 7, 10, 16). Günümüzde kamu sağlık hizmetlerinin yanı sıra bazı firmalar, şirket ürünleri ile ilgili bakım ve uzmanlık gerektiren son derece yararlı ekipman ve tamamlayıcı bakım hizmetlerini perinatoloji hemşireleriyle birlikte çalışarak sunmaktadır. Bununla beraber hizmetler her ne kadar iyi olsa da ürün odaklı olabilmektedir. Ayrıca özel sigortalar tarafından da doğum yapmış kadınlara ve bebeklerine hizmet sunmak adına bir ev ziyareti gerçekleştirilmekte evde lohusaya eğitim verilmektedir.

Günümüzde perinatoloji hemşireliği diğer profesyonel alanlarda olduğu gibi kanıta dayalı uygulamaları benimseyecek şekilde değişim göstermektedir. Bu nedenle çeşitli ülkelerin perinatoloji alanında kullandıkları çeşitli protokol ve yönergeler eşliğinde uygulamalar standardize edilmektedir. Bunların dıșında perinatoloji alanında evde bakımın etkinliğini artırmak adına çeşitli modeller de geliştirilmektedir. Ülkelere özgü modeller olabildiği gibi, gebenin sağlık durumuna uygun ya da riskli alışkanlık, sosyo-ekonomik durum gibi özelliklerine uygun olarak farklılaşmış modeller kullanılmaktadır $(7,10)$. Özellikle Avrupa'da aile merkezli bakım programları ile anne çocuk sağlığını koruma ve geliştirmeye yönelik hedefler oluşturulmaktadır $(7,10,20)$.

Günümüzde gerek Avrupa'da gerek ülkemizde perinatoloji hemşiresi değişen ve gelişen uygulamalar sayesinde daha sistematik ve planlı bir çalışma ile hasta bakım ve takibinde kanıta dayalı olarak rollerini yerine getirebilmektedir. Her yıl ulusal ve uluslararas 1 düzenlenen perinatoloji hemşireliği kongreleri, perinatoloji hemşireliği sertifika programları sayesinde güncel bilgilere ulaşabilmektedir. Hastanelerde son yıllarda gündemde olan kalite geliştirme uygulamaları her alanda olduğu gibi perinatoloji alanında da etki sağlamıştır. Standart protokoller oluşturma, kontrol listeleri ile hasta izlemi, hasta güvenliği skalaları ve protokolleri perinatoloji alanında da hemşirelerin sıklıkla kullandığ formlar olup, uygulamada standardizasyon sağlamakta ve kaliteyi artırmaktadır.

Eskiden perinatoloji hemşiresi özellikle, antenatal bakımda rol üstlenirken, günümüzde prekonsepsiyonel bakımdan postnatal dönem bakımına kadar her alanda rol ve görevler üstlenmektedir. Yine eskiden gebe eğitim, izlem ve bakımı üzerinden giden hizmetin yerini, günümüzde ebeveyn bilgilendirme ve eğitiminin bütüncül yaklaşımının aldığı da söylenebilir. Gebe okulları ile perinatoloji hemşireleri çiftlere birlikte gebelik, doğum, bebek bakımı gibi konularda eğitim vermektedir (21). Kamu, üniversite ya da özel hastanelerde gebe ve ailesine hizmet sunan gebe okulları ile doğuma hazırlık ve danışmanlık merkezleri için zamanın ihtiyaç ve beklentilerine uygun hizmet sunumu adına Sağlık Bakanlığınca standartlar da belirlenmiștir (22).

Ayrıca teknolojinin gelişmesi, akıllı telefon kullanımının oldukça yaygınlaşması her alanda olduğu gibi perinatoloji alanında da hizmet sunumuna katkı sağlamaktadır. Dünyada mobil sağlık uygulamaları perinatoloji alanında sıklıkla kullanılmaya başlanmış ve çeşitli şekillerde farklı gruplara uygun özgünlükte geliştirilmiştir. Prekonsepsiyonel döneme özgü beslenme ve folik asit kullanımını destekleyen, sigara, alkol kullanımını engellemeye yönelik aplikasyonlar olduğu gibi (23), gebelik süresince genel bilgilendirmeler içeren; bebeğin gelişimi, sağlıklı yaşam biçimi, kontrol zamanlarını hatırlatan sesli mesaj/kısa mesaj bildirimleri şeklinde takipler yapılabilmektedir (24). Yine postnatal dönem doğum sonu bakıma yönelik uygulamalar (aplikasyonlar) ile beraber bebek bakımına yönelik bilgilendirmeler içeren hizmetler sunulabilmektedir (25). Teknolojinin gelişimi sayesinde evde bakımda avantaj sağlayacak tele ultrason, fetal kalp sesi (Non Stress Test: NST) cihazına alternatif olarak kullanılabilecek mobil doppler (mDoppler) gibi cihazlar hastaneye gitmeden ihtiyacı olan tüm gebelerin evde takibini kolaylaştırmaktadır (26).

Ülkemizde de yine bazı özel hastanelerin sunduğu bir hizmet olarak mobil bilgilendirme platformları da bu amaçla kullanılmaktadır. Bunların yanı sıra gebelik okulları, gebelikte yoga sınıfları gibi eğitim ve danışmanlık içeren hizmetler son yıllarda oldukça sık sunulmakta ve bu eğitim merkezlerini çoğunlukla hemşireler yönetmektedir. Ayrıca bu tip gebelik okulları ya da konferanslar ücretsiz olarak gerek özel hastanelerde gerekse devlet hastaneleri ile toplum sağlığı merkezlerinde gebe ve ailelerine verilmektedir. Bunların yanı sıra sağlık kurumlarında gebelik, doğum ve emzirmeye yönelik hazırlanmış, broşür veya kitapçıklar da verilmektedir. Yine ülkemizde pek çok hastanede emzirme 
danışmanlığı hizmeti vermek üzere özel eğitim almış hemşireler ile emzirme sorunları, meme bakımı, mastit bakımı hizmetleri ve danışmanlığı yapılmaktadır (27).

Sağlık alanında küreselleşmenin ve teknolojinin etkisi ile her geçen gün değişim ve gelişim yaşanmaktadır. $\mathrm{Bu}$ durumun doğal yansımaları, değişen sosyodemografik yap1, yeni nüfus planlaması, ebeveynliğe yönelik değişen kültürel bakış açısı gibi etkilerin perinatoloji hemşireliğinin rol ve görevlerine olumlu etkileri olduğu söylenebilir. Hastane yatışlarının kısalması ile evde bakım ve izlemin artması, beraberinde perinatoloji alanında evde bakımın daha fazla önem taşıyan bir alan olmasını gündeme getirmektedir.

Ülkemiz şartlarında kadın sağlığı kapsamında jinekoloji, perinatoloji, cinsel/üreme sağlığı, infertilite ve menopoz gibi özel bölümlerde çalışacak olan hemşireler için eğitim gereksinimi tartışılmaktadır. Başka alanlarda olduğu gibi kadın sağlığı hemşireliğinde de lisansüstü eğitimin yaygınlaştırılması, kadın sağlığı alanında uzmanlaşan hemşirelerin görev ve yetkilerinin uluslararası düzeyde değerlendirilerek geliştirilmesi ve yasalarla desteklenmesi gerekmektedir (19). Böylelikle lisansüstü eğitimlerle perinatoloji gibi özel alanlarda daha donanımlı olan hemşirelerin bilgi ve deneyimlerini sahaya aktarabilmeleri ile bakım kalitesi artacaktır.

\section{SONUÇ}

Postpartum/doğum sonu dönem bakımı, faydaları çeşitli bilimsel araştırma sonuçlarıyla kanıtlanmış, önemli bir kadın sağlığı hizmetidir. Bu hizmet sayesinde kadın ve bebek sağlığını koruma ve geliştirme imkanı sunulmaktadır. Avrupa'da perinatoloji alanında evde bakımın uzun yıllardır sistemli şekilde uygulandığı gerek prenatal gerek postnatal dönem için özel durumlara özgün modeller geliştirildiği dikkat çekmektedir. Ülkemizde ise perinatal evde izlem veya bakımın bu denli sistematik ve düzenli bir şekilde yapıldığını söylemek güçtür. Özellikle postpartum/ doğum sonu dönemde lohusaların evde izleminin önemi şüphesizken istenilen düzeyde ev ziyaretlerinin gerçekleştirilmemesinin nedenleri araştırılmalıdır. Farklı ülkelerde teknolojinin perinatal izlemde yoğun olarak kullanıldığı görülmektedir. Gerek çeşitli telefon uygulamaları ile gerekse kamera ve telefon görüşmeleri ile gebe ve lohusalarla iletişim sağlanmakta, takip ve değerlendirmeleri yapılabilmektedir. Sağlık personelinin her lohusayı düzenli olarak ziyaret etmesinin; iş yoğunluğu, personel yetersizliği, ulaşım güçlüğü gibi nedenlerle zor olması bu konunun değerlendirilmesini gündeme getirebilir. Doğum sonu kadının ve bebeğin izlenebileceği basit bir telefon uygulaması ile risk belirlenebilir böylece risk düzeyi yüksek lohusalara telefon ve ev ziyareti planlanabilir. Telefon uygulaması (aplikasyon) lohusanın postpartum depresyon açısından psikolojik durumunu değerlendiren, kanama ve enfeksiyon gibi durumları belirtmeyi sağlayan birkaç basit kontrol/işaret listelerinden oluşabilir. Aynı şekilde bebeğin beslenme ve sarılık gibi acil durumlarını ölçen birkaç maddelik kontrol listeleri oluşabilir. Kadının günlük olarak bu telefon uygulaması üzerinden dolduracağı küçük bir kontrol/işaret listesi aile sağlığı merkezleri veri tabanlarına ulaşabilir, böylece lohusa ve yenidoğanın durumu uzaktan değerlendirilebilir. Teknolojiden de yararlanılabilecek olan bu örnekte olduğu gibi çeşitli farklı yöntemler doğum sonu dönem evde izlem için uygulanabilir. Dolayısı ile ülkemizde perinatoloji alanında özellikle doğum sonu dönemde ev ziyaretlerine daha fazla önem verilmesi ve bu konuda dünyadaki yenilikler örnek alınarak çeşitli programlar oluşturulması ve teknolojiden daha fazla yararlanılması önerilebilir.

\section{KAYNAKLAR}

1. Büyükkayacı N, Karatas N. Sezaryen sonrası erken taburcu olan kadınlara verilen evde bakım hizmetinin anne sağlığına ve öz bakım gücüne etkisi. Sağlık Bilimleri Dergisi. 2011; 20(1): 54-67.

2. Balkaya NA. Postpartum dönemde annelerin bakım gereksinimleri ve ebe - hemşirenin rolü. Cumhuriyet Üniversitesi Hemşirelik Yüksekokulu Dergisi. 2002; 6(2): 42-9.

3. Koç GI, Eroğlu K. Evde bakım hizmetlerinin doğum sonu erken taburcu edilen yenidoğanlarda görülen komplikasyonlar üzerine etkisi. Hacettepe Üniversitesi Sağl1k Bilimleri Fakültesi Hemşirelik Dergisi. 2009; 16(1): 25-38.

4. Brooten D, Youngblut JM, Donahue D, Hamilton M. Women with high-risk pregnancies, problems, and APN interventions. Journal of Nursing Scholarship. 2007; 39(4): 349-57.

5. Atıcı İ. Doğum sonu erken taburculukta lohusalara verilecek sağlık eğitimi ve evde bakımın postpartum komplikasyonlar ve anksiyete düzeyine etkisi. Bilim uzmanlığı tezi, A.Ü. Sağlık Bilimleri Enstitüsü Halk Sağlığı. Erzurum, 2000.

6. Parastoo A, Marjan V, Malekkhahi A, Behnaz A, Maryam G, Vaziri SM, et al. Doğum sonrası ev ziyareti eğitim programının yenidoğanlarda anne sütü ile beslenme üzerine etkisi: randomize klinik bir çalışma. Çukurova Medical Journal. 2017; 42(3): 407-12.

7. Mcginnis S, Lee E, Kristen K, Miranda-Julian C. Let's talk about breastfeeding: the importance of delivering a message 
in a home visiting program. American Journal of Health Promotion. 2018; 32(4): 989-96.

8. Dahlberg U, Haugan G, Aune I. Women's experiences of home visits by midwives in the early postnatal period. Midwifery. 2016; 39: $57-62$.

9. Gölbaşı Z. Pospartum dönemde erken taburculuk, evde bakım hizmetleri ve hemşirelik. Cumhuriyet Üniversitesi Hemsirelik Yüksekokulu Dergisi. 2003; 7(2): 15-22.

10. Goldfeld S, Price A, Bryson H, Bruce T, Mensah F, Orsini F, et al.right@home': A randomised controlled trial of sustained nurse home visiting from pregnancy to child age 2 years, versus usual care, to improve parent care, parent responsivity and the home learning environment at 2 years. BMJ Open 2017;7:e013307. doi:10.1136/bmjopen.013307, 2016.

11. Mitra M, Akobirshoev I, Moring NS, Long-Bellil L, Smeltzer $\mathrm{SC}$, Smith LD, et al. Access to and satisfaction with prenatal care among. Jornal of Women's Health. 2017; 26(12): 135663.

12. Toplum Sağlı̆̆ı Merkezi ve Bağlı Birimler Yönetmeliği. 5 Şubat 2015 Resmi Gazete Sayı:29258. URL: https://www. resmigazete.gov.tr/eskiler/2015/02/20150205-5.htm. 2015.

13. Aile Hekimligi Uygulama Yönetmeliği. 25 Ocak 2013 Resmi Gazete Say1:28539. URL: https://www.mevzuat. gov.tr/mevzuat? MevzuatNo=17051\&MevzuatTur=7\& MevzuatTertip=5. 2013 .

14. Simpson RK, Creehan PA. Perinatal Nursing 2nd Edition. Lippincott Company, Philadelphia 2001: 446-667.

15. Kobayashi H, Sado T. Satisfaction of a new telephone consultation service for prenatal and postnatal health care. The Journal of Obstetrics and Gynecology Research. 2019; 45(7): 1376-81.

16. Batman $\mathrm{D}$, Şeker $\mathrm{S}$. Web tabanlı eğitimin prematüre yenidoğanların ebeveynlerinin bakımdaki özgüven ve kayg1 düzeylerine etkisi. Dokuz Eylül Üniversitesi Hemşirelik Fakültesi Elektronik Dergisi. 2019; 12(2): 107-15.

17. Curran L. The women's health nurse practitioner. Evolution of a powerful role. AWHONN Lifelines. 2002; 6(4): 332-7.
18. Merih YD, Potur DC. Perinatolojide hemşirenin gelişen ve değişen rolleri. Türkiye Klinikleri Doğum-Kadın Sağlığı ve Hastalıkları Hemşireliği-Özel Konular. 2018; 4(2): 61-9.

19. Güngör İ, Rathfish G, Beji NK. Kadın sağlığı hemşirelerinin rol yetki ve sorumluluklarının uluslararsı düzeyde irdelenmsi. Florance Nightingale Hemşirelik Dergisi. 2013; 21(1): 4956.

20. Mejdoubi J, Heijkant S, Leeerdam F, Crone M, Crijnen A, Hirasing RA. Effecys of nurse home visiting on cigarette smoking, pregnancy outcomes and breastfeeding: a randomized controlled trial. Midwifery. 2014; 30(6): 688-95.

21. Okumuş H, Yenal K, Ozan YD. Ülkemizde doğuma hazırlık sınıflarına ilişkin yapılan bilimsel çalışmalar: literatür derlemesi. Turkiye Klinikleri Obstetric-Women's Health and Diseases Nursing. 2015; 1(1):16-24.

22. Sağlık Hizmetlerinde Gebe Bilgilendirme Sınıfı, Gebe Okulu ve Doğuma Hazırlık ve Danışmanlık Merkezlerinin çalışma Usul ve Esasları. URL: https://dosyamerkez.saglik.gov.tr/ Eklenti/27473, gebe-okulu-gebe-bileke093068a-ccaf-4c37aa08-7886ae9fa1e5pdf.pdf?0.

23. Van Dijk MR, Koster MP, Willemsen SP, Theunissen RP. Healthy preconception nutrition and lifestyle using personalized mobile health coaching is associated with enhanced pregnancy change. Reproductive Biomedicine Online. 2017; 35(4): 453-60.

24. Greiner AL. Telemedicine applications in obstetrics and gynecology. Clinical Obstetrics and Gynecology. 2017; 60(4): 853-66.

25. Balakrishnan R, Gopichandran V, Chaturvedi S, Chaudhuri I. Continuum of care services for maternal and child health using mobile technology-a health system strengthening strategy in low and middle income. BMC Med Inform Decis Mak 16, 84 (2016). https://doi.org/10.1186/s12911.016.0326-z.

26. Yüksel MU. Fetal kalp hızı monitörizasyon sistemi (FKHMS) ve mobil entegredoppler (M-DOPPLER). İstanbul Aydın Üniversitesi Bilgisayar Mühendisliği Ana Bilim Dalı Bilgisayar Mühendisliği Programı Yüksek Lisans Tezi, İstanbul. 2017.

27. Özkara H, Fidancı BE, Yıldız D, Kaymakamgil Ç. Emzirme danışmanlığ . Preventive Medicine Bulletin TAF. 2016; 15(6): 551-5. 